\title{
Manejo da adesão a tratamentos de doenças crônicas: experiências de Agentes Comunitários de Saúde
}

\section{Management of adherence to chronic diseases treatments: experiences of Community Health Workers}

\section{Gestión de la adherencia al tratamiento de enfermedades crónicas: experiencias de los Agentes de Salud Comunitarios}

\section{Kelly Cristina Nascimento ${ }^{1}$, Lilian Maria Borges ${ }^{2 *}$}

Como citar esse artigo. Nascimento, KC; Borges, LM. Manejo da adesão a tratamentos de doenças crônicas: experiências de Agentes Comunitários de Saúde. Revista Pró-UniverSUS. 2020 Jul./Dez.; 11 (2): 10-18.

\section{Resumo}

No contexto da Atenção Básica à Saúde ocorrem ações integradas de educação e cuidado a pessoas com doenças crônicas através de ações das equipes de Saúde da Família, o que inclui o trabalho dos agentes comunitários de saúde. Espera-se que esses agentes disponham de conhecimentos e habilidades para favorecer a promoção de saúde e a prevenção e controle de doenças na população atendida. O objetivo do estudo foi investigar o manejo por agentes comunitários de saúde de aspectos psicossociais que influenciam a adesão aos tratamentos de usuários com Hipertensão Arterial e/ou Diabetes Mellitus. Participaram dezesseis agentes comunitários atuantes em um município do estado do Rio de Janeiro, RJ/Brasil, divididos em três grupos focais. Os dados coletados foram categorizados e analisados conforme a Análise de Conteúdo de Bardin. Os resultados mostraram que, para lidar com problemas de adesão, os participantes utilizavam repertório de ação diversificado, estratégico e criativo, voltado tanto para a intervenção direta com os usuários como para a busca de apoio junto a outros profissionais e a familiares. A participação no grupo focal revelou-se uma oportunidade de reflexão e aperfeiçoamento profissional, possibilitando a troca de experiências entre os agentes comunitários e uma maior conscientização sobre a importância de suas práticas.

Palavras-chave: Adesão ao Tratamento, Agentes Comunitários de Saúde, Atenção Primária à Saúde.

\begin{abstract}
In the context of Primary Health Care, there are integrated actions of education and care for people with chronic diseases through the actions of the Family Health teams, which includes the work of community health workers. These workers are expected to have knowledge and skills to facilitate health promotion and disease prevention and control in the assisted population. The objective of the study was to investigate the management by community health workers of psychosocial aspects that influence adherence to the treatment of users with Arterial Hypertension and/or Diabetes Mellitus. Sixteen community workers working in a municipality in the state of Rio de Janeiro participated, divided into three focus groups. The collected data were categorized and analyzed according to Bardin's Content Analysis. The results showed that, in order to deal with adherence problems, participants used a diversified, strategic and creative repertoire of action, aimed both at direct intervention with users and at seeking support from other professionals and family members. Participation in the focus group proved to be an opportunity for reflection and professional improvement, enabling the exchange of experiences between community workers and greater awareness of the importance of their practices.
\end{abstract}

Keywords: Treatment Adherence, Community Health Workers, Primary Health Care. 


\section{Resumen}

En el contexto de la Atención Primaria de Salud, se realizan acciones integradas de educación y atención a las personas con enfermedades crónicas a través de las acciones de los equipos de Salud de la Familia, lo que incluye el trabajo de los agentes comunitarios de salud. Se espera que estos agentes tengan conocimiento y habilidades para promover la promoción de la salud y la prevención y el control de enfermedades en la población atendida. El objetivo del estudio fue investigar el manejo por parte de los agentes comunitarios de salud de los aspectos psicosociales que influyen en la adherencia al tratamiento de los usuarios con Hipertensión Arterial y/o Diabetes Mellitus. Participaron 16 agentes comunitarios que trabajan en un municipio del estado de Río de Janeiro, divididos en tres grupos focales. Los datos recopilados se categorizaron y analizaron de acuerdo con el análisis de contenido de Bardin. Los resultados mostraron que, para abordar los problemas de adherencia, los agentes utilizaron un repertorio de acción diversificado, estratégico y creativo, enfocado tanto a la intervención directa con los usuarios como a la búsqueda de apoyo de otros profesionales y familiares. La participación en el grupo focal resultó ser una oportunidad de reflexión y desarrollo profesional, posibilitando el intercambio de experiencias entre agentes comunitarios y una mayor conciencia de la importancia de sus prácticas.

Palabras clave: Adherencia al Tratamiento, Agentes Comunitarios de Salud, Atención Primaria de Salud.

\section{Introdução}

AAtenção Básica à Saúde (ABS) visa desenvolver uma atenção integral que impacte na situação de saúde e autonomia dos indivíduos e nos determinantes e condicionantes de saúde das coletividades. Segundo suas diretrizes, deve ser realizada no território, ser acolhedora, resolutiva e favorecer o avanço da gestão e coordenação do cuidado aos usuários ${ }^{1}$. O trabalho diretamente nos locais onde se desenrola o cotidiano das pessoas auxilia no processo de cuidar, pois revela componentes significativos para a saúde da população, tais como moradia, saneamento básico, interação social e segurança pública².

A Saúde da Família, enquanto estratégia prioritária da $\mathrm{ABS}$, busca reorientar o modelo de atenção à saúde ao aproximar profissionais e comunidade e, por conseguinte, contribui para romper com um modelo de assistência focado em ações curativas e remediadoras, de modo a oferecer serviços comprometidos com a saúde integral dos usuários. Funciona como a porta de entrada no sistema de saúde e possibilita que as ações de caráter comunitário sejam mais eficazes ${ }^{3}$. A proximidade entre os serviços e a comunidade oportuniza a escuta sensível dos usuários para que se sintam acolhidos e inseridos de maneira proativa na produção do cuidado ${ }^{4}$.

Em termos de configuração, as equipes de Saúde da Família são constituídas pelos seguintes profissionais: médicos, enfermeiros, cirurgiões-dentistas, auxiliares em saúde bucal ou técnicos em saúde bucal, auxiliares de enfermagem ou técnicos de enfermagem e Agentes Comunitários de Saúde (ACS), entre outros profissionais definidos em função da realidade epidemiológica, institucional e das necessidades de saúde da população ${ }^{3}$. Nesse contexto multiprofissional, os ACS desenvolvem ações diversas no intuito de favorecer a integração entre as famílias e a equipe de saúde, sendo responsáveis por atividades como adscrição das famílias, cadastramento das pessoas de sua microárea, orientação sobre a utilização dos serviços de saúde disponíveis, visitas domiciliares, ações educativas e desenvolvimento de atividades de promoção da saúde, prevenção de doenças e agravos e monitoramento de grupos ou problemas específicos ${ }^{3,5}$.

A profissão foi regulamentada mediante a Lei $\mathrm{n}^{\circ}$ $10.507 / 2002^{6}$, que estabelece os critérios e pré-requisitos mínimos para a contratação desse profissional, incluindo residir na comunidade em que irá atuar, ter concluso o ensino fundamental e concluir com aproveitamento o curso de qualificação básica para a formação de ACS. Trata-se, portanto, de moradores da própria comunidade, com ela identificados, na medida em que compartilham dos mesmos costumes, valores e linguagem. Por outro lado, ao serem selecionados, necessitam ser capacitados e acompanhados por outros integrantes das equipes de saúde, de modo a contribuírem na implementação de ações educativas e preventivas com potencial para fortalecer a organização e o desenvolvimento comunitário ${ }^{7}$.

As competências profissionais esperadas dos ACS devem ir além do nível de produção burocrática. É necessário, por exemplo, que saibam distinguir entre promoção da saúde e prevenção de doenças, com compreensão dos limites conceituais e práticos desses conceitos essenciais no nível primário de atenção ${ }^{8}$. Ademais, o fato de serem inseridos no contexto de vida das famílias, requer uma visão ampla dos múltiplos aspectos associados às condições de vida da população atendida. Assim, através do seu vínculo com a comunidade, podem exercer um papel social diferenciado em comparação a outros profissionais da saúde.

Uma das contribuições esperadas dos ACS diz respeito a ajudar os usuários a melhor aderirem a seus planos de tratamento, o que inclui a distribuição de medicamentos para as famílias de sua área ${ }^{6}$, além de orientações e estímulos para o autocuidado?. Nesse sentido, agentes comunitários têm destacado 
a importância de orientações às famílias com vista ao uso racional de medicamentos e ao fortalecimento de hábitos de vida saudáveis, como alimentação adequada e prática regular de exercícios físicos ${ }^{10}$.

É nesse contexto da atenção primária que ocorrem, prioritariamente, ações integradas de prevenção e cuidado a pessoas com Hipertensão Arterial (HA) e Diabetes Mellitus (DM) ${ }^{11}$. Tais doenças têm em comum a cronicidade e, se não forem devidamente controladas, elevam os riscos para comorbidades e outras complicações à saúde que podem ser evitadas e/ ou minimizadas se houver adesão adequada ao plano terapêutico. O termo DM abarca um grupo de doenças metabólicas caracterizadas por níveis elevados de glicose no sangue, decorrentes de defeitos na secreção e/ ou na ação da insulina ${ }^{6,12,13,14}$. A hiperglicemia pode gerar complicações clínicas como retinopatia, arteriosclerose, nefropatia, neuropatia e pé diabético. A HA, por sua vez, é caracterizada pela elevação da pressão arterial, considerada como um dos principais fatores de risco para infarto agudo do miocárdio, acidente vascular encefálico e insuficiência renal ${ }^{15,16}$.

Para maior eficácia no tratamento dessas doenças, o Ministério da Saúde implantou, em 2001, o Plano de Reorganização da Atenção à Hipertensão Arterial e ao Diabetes Mellitus (PRAHADM), cujo propósito é vincular as pessoas que vivenciam esses agravos às unidades de saúde, garantindo-lhes acompanhamento e tratamento sistemático, mediante ações de capacitação dos profissionais e de reorganização dos serviços. Como um sistema de cadastramento e acompanhamento de usuários com esses diagnósticos, foi constituído um programa nacional conhecido como Hiperdia, que proporciona o fornecimento contínuo e gratuito de medicamentos, além do monitoramento das condições clínicas de cada usuário ${ }^{17}$. Entretanto, o acesso facilitado aos medicamentos e às orientações acerca dos cuidados necessários ao controle dessas doenças nem sempre são suficientes para que os usuários realizem adequadamente os tratamentos propostos. Tal fato pode impactar significativamente tanto em suas condições clínicas como na eficácia e custos dos serviços de saúde, requerendo, como consequência, novas consultas médicas, tratamentos mais complexos e dias adicionais de licença do trabalho.

Aadesão ao tratamento é definida pela Organização Mundial da Saúde (OMS) como a medida com que o comportamento da pessoa corresponde às prescrições e recomendações recebidas dos profissionais de saúde, o que inclui tomar medicações, seguir dietas e/ou mudar o estilo de vida. A despeito da importância de uma boa adesão, níveis baixos de seguimento do tratamento de doenças crônicas configuram-se como um problema mundial, o que representa risco elevado à saúde, como o retorno de sintomas, aparecimento de complicações médicas e psicossociais, surgimento de resistência a medicamentos e redução na qualidade de vida ${ }^{18}$.

Nesse sentido, a compreensão da relação entre aspectos psicossociais e comportamentos de adesão a tratamentos de variadas doenças tem sido necessária para o aprimoramento de políticas públicas e para o planejamento de estratégias de intervenção multidisciplinares ${ }^{19}$. A OMS compreende a adesão como um fenômeno multidimensional, que envolve a interação de cinco grupos de fatores, relacionados a aspectos socioeconômicos, aos sistemas e profissionais da saúde, à própria terapia, às condições de saúde e às características dos pacientes18. Nessa direção, estudos têm sido realizados na busca por compreender os fatores que atuam nesse processo para, assim, delinear programas de intervenção na área ${ }^{20,21,22,23}$.

É preciso que os programas educativos voltados para a melhoria da adesão em doenças crônicas sejam baseados não somente em disseminação de informações, mas que contemplem também aspectos psicossociais, como crenças e preocupações acerca da doença e seu tratamento ${ }^{24}$. Diretrizes gerais para favorecer a adesão aos tratamentos, dentre elas: relação cordial, estímulo ao paciente para conhecer e incorporar como seu o compromisso do cuidado, orientações sobre a doença, revisão de crenças e expectativas errôneas, adaptação das orientações às demandas e interesses do paciente, estabelecimento de metas terapêuticas e negociações de trocas de medicação quando necessário ${ }^{25}$.

Na pesquisa aqui relatada, pretendeu-se investigar como os ACS lidam com possíveis dificuldades relacionadas a baixa adesão aos tratamentos no cotidiano de trabalho da ABS de um município do estado do Rio de Janeiro RJ/Brasil, de modo a conhecer como têm atuado no favorecimento da adesão aos esquemas terapêuticos propostos para usuários diagnosticados com Hipertensão Arterial Sistêmica (HAS) e/ou DM assistidos no programa Hiperdia.

\section{Metodologia}

A pesquisa foi desenvolvida com 16 ACS atuantes em três Estratégias de Saúde da Família (ESF) de um município localizado na Região da Costa verde do estado do Rio de Janeiro/Brasil. Atuavam nestas unidades um total de 64 ACS. Os profissionais que integraram o estudo apresentavam média de idade igual a 33 anos e a maioria era do gênero feminino (94\%). Eles foram divididos em três grupos focais de cinco ou seis participantes, nomeados como GFA, GFB e GFC.

Para coleta dos dados foram utilizados um questionário para caracterização sociodemográfica dos respondentes e obtenção de informações relativas à formação acadêmica e ao trabalho na ABS, além de um roteiro para condução de grupo focal, cujos principais eixos foram: conceito de adesão ao tratamento e 
avaliação da adesão dos usuários atendidos; identificação de fatores que dificultam e que favorecem a adesão; intervenções utilizadas na promoção de adesão aos tratamentos de hipertensos e diabéticos e capacitação/ atualização existente ou desejada.

O projeto de investigação foi submetido à análise do Comitê de Ética na Pesquisa da Universidade Federal Rural do Rio de Janeiro, sendo aprovado sob parecer $\mathrm{N}^{\mathrm{o}} 23083.011215 / 2016-54$, protocolo $n^{\circ} 858 / 2016$. Em seguida, foram realizados encontros presenciais com enfermeiras-gerentes de três regiões do município, tendo em vista explicações sobre a pesquisa e solicitação de apoio na abordagem aos ACS. Em reuniões previamente agendadas, foi feito o convite verbal aos ACS para participação na coleta de dados e foram fornecidas informações iniciais a respeito.

Nos dias acordados com os ACS, o grupo focal foi realizado na unidade de saúde correspondente. Ao iniciar o encontro, foi entregue aos participantes um Termo de Consentimento Livre e Esclarecido, que foi lido e assinado por cada um deles. Logo após, o questionário sociodemográfico e profissional foi aplicado de modo autoadministrado. Na sequência, realizou-se o grupo focal, com apresentação e discussão de cada uma das questões disparadoras previamente elaboradas. Houve a gravação em áudio das falas apresentadas durante os encontros, o que possibilitou a transcrição dos relatos na íntegra.

O material reunido nos encontros foi submetido a procedimentos da Análise de Conteúdo ${ }^{26}$. Foram feitas leituras repetidas e exaustivas dos relatos transcritos e, posteriormente, em cada eixo de análise, foi realizado o agrupamento do conteúdo das falas por similaridades e sentidos. Categorias temáticas foram, então, elaboradas, nomeadas e descritas. A partir daí, procedeu-se a interpretação e discussão dos dados com base na literatura vigente.

\section{Resultados e Discussão}

$\mathrm{Na}$ busca pelo entendimento de como os ACS agiam junto a usuários com DM e/ou HA que não apresentavam boa adesão aos seus tratamentos, foi possível construir sete categorias temáticas a partir das falas registradas nos grupos focais. São elas: controlar, orientar, criar estratégias facilitadoras, mostrar atenção, buscar auxílio profissional, envolver a família e favorecer o acesso a medicamentos e serviços. As quatro primeiras categorias dizem respeito ao conjunto de respostas utilizadas pelos agentes, com base em suas aptidões e experiências, para auxiliar os usuários em seus processos de tratamento. As três seguintes consistem em buscar, no meio institucional ou no grupo familiar, o apoio e os recursos necessários para favorecer a adesão no contexto de cuidado aos usuários.
No que tange a categoria "controlar", o agente observava o usuário em seu contexto de vida diária e, diante de evidências de não adesão, dava comandos para a ação, fiscalizava o uso dos medicamentos, persuadia, dava "broncas" ou cobrava responsabilidades do usuário, como mostram os exemplos a seguir:

Eu chamo a atenção da paciente: a senhora não pode deixar de tomar o remédio, sabe que não pode. Eu já peguei paciente em bar bebendo e briguei com ele. Se tiver uma receita vencida, eu vou brigar. Não tem que ter receita vencida. (GFA)

$\mathrm{Eu}$ já fui várias vezes na casa dos pacientes colocar o remédio na mão deles para tomar na minha frente. (GFB)

Conto os remédios como forma de saber se estão tomando. Peço para ver se está na validade. Eu sei que está, mas serve como estratégia para contar a quantidade. (GFB)

Cobro responsabilidade do paciente para o cuidado dele, de ir às consultas e pegar seus remédios. (GFC)

Comopodeserobservadonosrelatos apresentados, alguns agentes se colocavam em posição de cobrança e fiscalização, chegando inclusive a dar o remédio na mão do usuário, buscá-lo no bar ou persuadi-lo a ir à consulta. Como dito por uma das participantes, "de tanto a gente ser chato, eles acabam fazendo o que a gente pede" (GFA). Essa forma de agir ainda que gere concordância não garante resultados duradouros, pois estes tendem a ser momentâneos, muitas vezes ocorrendo apenas na presença da figura coercitiva. Não gera conscientização, independência ou autonomia, pois funciona como um cuidado tutelar, que entende o outro como incapaz de cuidar de si ${ }^{14,15}$

A adesão não diz respeito a mera obediência ou fidelidade às orientações médicas, antes disso implica na possibilidade de o usuário compreender, concordar e participar ativamente das decisões acerca do seu tratamento, o que pressupõe uma responsabilidade compartilhada entre paciente, família e equipe de saúde. Nesse sentido, deve ser vista como uma atividade conjunta, na qual o usuário passa a ser participante ativo do seu cuidado ${ }^{18}$. Embora o controle possa se mostrar necessário em algum momento, é preciso, a partir de então, construir estratégias para produzir maior engajamento do usuário ${ }^{14,15}$.

Ainda que seja necessário evitar ações coercitivas, cabe destacar que as visitas domiciliares facilitam aos agentes observarem in loco o contexto de vida de cada usuário, não se ancorando apenas em relatos verbais. Sabe-se que a adesão é de difícil avaliação e mensuração, baseando-se, quase sempre, nos relatos do próprio indivíduo, que tendem a ser falhos, já que este pode esquecer, omitir ou distorcer informações. Mediante observação e sondagem, o ACS faz o reconhecimento dos problemas que existem no território, atentos às 
intervenções necessárias ${ }^{20}$.

Todavia, essas formas de acompanhamento, por vezes, eram acompanhadas de resistência e, até mesmo, de agressividade, como informado por integrantes do GFA, embora estes julgassem que, no final, os usuários acabavam acatando as orientações recebidas. Em suas palavras: "Já teve paciente na minha área que me xingou de tudo que era nome, que eu não tinha que estar na porta dele"; "Quando você passa [em frente ao bar], eles até se escondem. Daí a gente vai, orienta que não é assim, chamamos para ir à unidade. Eles ficam na maior guerra, mas depois acabam aceitando". $\mathrm{O}$ fato de o agente morar no local de atuação favorece um envolvimento tanto profissional como pessoal nos problemas que ele presencia, gerando situações difíceis de administrar já que sua relação profissional deve ser distinta daquele que estabelece como morador ${ }^{7}$.

$\mathrm{Na}$ categoria "orientar", o agente buscava conversar com o usuário acerca das características e necessidades do tratamento para o controle de seu quadro clínico. Nesse intuito, propiciava explicações e orientações que julgava pertinentes, esclarecia dúvidas, apontava consequências negativas da não adesão e/ ou conscientizava sobre os benefícios de seguir as prescrições recebidas.

Conforme a narrativa dos participantes: (GFA)

A gente orienta, a gente tenta passar o que sabe.

Oriento no uso correto da medicação, tem pacientes que cortam os comprimidos, tomam a mais ou a menos [...], tive que orientar para não exagerar na dosagem, pois vi que estava faltando na cartela. (GFB)

Falo dos riscos, complicações e benefícios do tratamento. (GFC)

Você fala para eles que não devem comer certas coisas e outras sim [...], aí você explica. (GFC)

$\mathrm{Eu}$ oriento que não pode tomar o remédio por conta própria, oriento ir até o médico, informar se está ou não se sentindo bem. (GFC)

No cotidiano de seus trabalhos, vários problemas de adesão têm sido identificados por ACS, tais como uso da medicação em horários e quantidade incorretos, automedicação, confusão da medicação da unidade de saúde com a que é adquirida em farmácias comerciais e dificuldade de entendimento das prescrições médicas. Em situações com estas, os ACS orientam as famílias nos cuidados relativos a horários, dose e validade das medicações, além do seu armazenamento adequado, ressaltam a importância de mudanças em hábitos de vida, além de encaminhar os usuários aos profissionais da ESF quando necessário ${ }^{10}$.

$\mathrm{Na}$ presente pesquisa, verificou-se a iniciativa dos agentes para clarear ou complementar orientações da equipe de saúde. Entretanto, pelas falas registradas nos grupos focais, não é possível afirmar se a conversa informada tratava-se, de fato, de uma relação dialógica, com sensibilidade às dificuldades dos usuários para colocar em prática o tratamento. Quanto ao conteúdo e a forma de passar informações, verificou que uma parte dos agentes participantes da sua pesquisa exibiam falas calcadas no modelo biomédico, sendo diretivos e com pontuações de certo e errado, reduzindo, assim, a possibilidade de vínculo e autonomia no cuidado ${ }^{27}$.

Vale ressaltar que não basta informar, é necessário compreender a singularidade do sujeito, que não pode ser visto como um receptor passivo do discurso promovido pela equipe. Uma escuta atenta e empática permite compreender e ter uma visão contextualizada de cada usuário, assegurando melhor atendimento de suas necessidades. Quanto mais eficiente for a comunicação, com clareza e adequação da linguagem na transmissão das informações, mais ativa tende a ser a participação do usuário nas ações e decisões que envolvem seu tratamento ${ }^{10}$.

$\mathrm{Na}$ categoria "usar estratégias facilitadoras", o agente usava a criatividade e informações prévias para melhor concretizar as orientações passadas pela equipe de saúde, o que incluía a elaboração de mapas de medicamentos, desenhos ilustrativos do horário das medicações e uso de cores nos potes de remédio para facilitar a visualização. As estratégias para ajudar no uso correto das medicações ocorriam, principalmente, quando o usuário manifestava dificuldades específicas, como surdez, déficit visual, dificuldades de memorização das informações ou analfabetismo.

Ele justifica que não enxerga, mas eu peguei uma folha e escrevi com letras grandes e coloquei na porta da geladeira dele. Eu disse a ele "Agora o senhor vai enxergar o que está escrito ali, a hora do remédio!" (GFB)

Escrevo, faço sol e lua para identificar com símbolos os horários dos remédios, se dia ou noite. Trabalho com a criatividade para paciente que não sabe ler nem escrever, idosos, os que se esquecem. (GFB)

Separo a medicação em potinhos com nome e símbolo para facilitar, tudo para tomarem a medicação. (GFB)

Tinha um paciente meu que não sabia ler. Toda vez que eu chegava na casa dele, os remédios estavam no saco. E ele dizendo que tinha tomado. Tomava os errados. Daí pedi orientação a enfermeira de como proceder nesse caso. Ela me ensinou a fazer copos, desenhando sol, sol com lua e lua para identificar os horários e os medicamentos já separados. Ele começou a tomar, eu fui orientando. (GFC)

Criamos estratégias por cor e por forma, o problema é quando muda o fabricante. (GFC)

Tem uns idosos que misturam remédios e não tomam, daí espera eu passar na casa deles para tomarem, pois não sabem ler [...]. Eu separo em potes de formatos diferentes. Me disse "minha filha, estou há uma semana sem tomar remédios, pois não te vi para me explicar". 


\section{(GFC)}

Observou-se que os agentes, com base no aprendizado do dia a dia e apoio de outros membros da equipe, vinham desenvolvendo estratégias de atuação criativas, buscando novas possibilidades de relacionamento e de intervenção junto aos usuários assistidos. De fato, muitas vezes os usuários, sobretudo quando idosos e/ou de baixa escolaridade, não sabem informar o nome da medicação utilizada ou a dose e frequência da sua ingestão ${ }^{28}$. Para facilitar a adesão nesses casos, o pictograma tem sido utilizado por meio do uso de figuras que auxiliam, por exemplo, na compreensão dos horários de tomada da medicação10. Estas formas de atuação denotam uma modificação no processo de trabalho, com surgimento de novas formas de responsabilização ${ }^{29}$.

No processo de cuidado a usuários não alfabetizados, em sua maioria idosos hipertensos e diabéticos, os agentes ouvidos em um estudo ${ }^{27}$ também utilizaram certos recursos para auxiliá-los na administração de suas medicações, como utilização de símbolos para facilitar a lembrança de horários. A criatividade e proatividade evidenciadas remeteram ao modelo biopsicossocial, preconizado na saúde como um olhar integral ao ser humano, para além de sua condição clínica limitadora.

A categoria "mostrar atenção" ocorria quando o agente se mostrava receptivo e disponível ao usuário com vistas a formar vínculos e facilitar a adesão, bem como quando lhe dedicava atenção no sentido de revelar seu esforço para compreendê-lo ou ajudá-lo, além de auxiliar na resolução de problemas relacionados à adesão. Ilustrações dessa categoria são apresentadas a seguir:

A tia filhinha não podia comer algumas coisas e tinha que emagrecer, daí eu falava para ela que ia almoçar com ela na casa dela, daí ela dizia que ia fazer legumes. E ela conseguiu emagrecer. (GFA)

Falar com jeitinho, ser repetitivo, perguntar por que não apareceu na unidade, tentar ficar íntimo da pessoa. (GFA)

Às vezes vamos a casa do paciente e ele só quer falar da vida. (GFA)

Busco estar sempre presente com o paciente, ter uma atenção maior com esse paciente [...] você mostra que está ali presente, mostrando preocupação. (GFB)

Aspectos culturais, comportamentais e de crenças em saúde exigem do ACS uma escuta apurada, observação atenta e respostas individualizadas às necessidades do usuário, de modo que este possa se sentir acolhido ${ }^{30}$. Comum a todos os atores em saúde, acolher é um modo de atender as demandas, assumindo uma postura de escuta e emitindo respostas pertinentes às necessidades observadas. A devida compreensão do que está acontecendo no aqui-agora com o usuário mediante postura atenta, compreensão individualizada e atitude empática favorece uma intervenção mais eficiente no processo do cuidado ${ }^{31}$.

Além disso, vale considerar que o agente de saúde, por sua relação de pertença ao meio em que não somente atua, mas também vive, pode ter uma experiência de trabalho permeada de solidariedade, já que as pessoas da sua realidade social são as mesmas das suas ações de cuidado. Essa identificação com a comunidade pode levá-lo a buscar o bem-estar desejado para o outro, como se fosse para si mesmo ${ }^{7}$.

As categorias seguintes apontam para o esforço dos participantes em buscar, nos casos de baixa adesão, ajuda junto a outros profissionais ou familiares. Eles reconheciam a necessidade de oferecer um auxílio mais técnico aos usuários, o que buscavam suprir no contato com médicos e enfermeiros ou no encaminhamento dos usuários para atendimento direto com estes. Ademais, viam os familiares como colaboradores no processo de adesão, cujo apoio necessitavam conquistar e valorizar.

A categoria "buscar auxílio profissional" indica que o agente, para realizar seu trabalho, pedia suporte técnico a outro(s) membro(s) da equipe de saúde, levando o problema identificado para discussão ou orientação sobre como devia proceder. Além disso, quando não se julgava competente o suficiente para as orientações, encaminhava o usuário para atendimento na unidade de saúde ou facilitava a visita domiciliar por outro profissional. A maioria dos participantes alegaram que tomavam estas medidas quando já haviam esgotado seus recursos, ou seja, quando as ações realizadas por eles não haviam surtido o efeito esperado.

Conforme seus relatos:

Trago para a enfermeira o problema, daí peço orientação, peço ajuda para solucionar. (GFA)

Se a gente não consegue ajudar, pede ajuda ao médico. [...] caso não consiga, passa para a enfermeira e para o médico, daí já é com eles. (GFA)

A gente coloca o médico, a enfermeira na situação e ele também ir conosco a casa do paciente, para examinar. (GFA)

Eu tenho um paciente que por achar que não está passando mal não precisa tomar o remédio, daí eu marco consulta e a médica orienta. (GFB)

Sempre tento conversar com o paciente e com a família. Quando vejo que não está surtindo efeito, não tem resultado, sempre passo o caso para a médica. (GFB)

As falas descritas mostram que os agentes, quando não se sentiam preparados o suficiente, "passavam" o caso para outros profissionais ou buscavam se instrumentalizar junto aos mesmos. O encaminhamento do usuário ou a facilitação do contato deste com outros membros da equipe indicou um discernimento dos participantes acerca dos papéis profissionais, quando o aprofundamento técnico torna necessário o envolvimento direto de um profissional mais habilitado 
para aquela função. A interação comunicativa entre ACS e demais profissionais da equipe permite maior eficácia na construção de um cuidado integral ao usuário ${ }^{32}$.

O ACS deve funcionar como um elo entre a comunidade, com seus costumes e valores, e a equipe multiprofissional, detentora de um conhecimento científico $^{7,10}$. No entanto, nem sempre eles se reconhecem dessa forma, havendo pouca interação destes com outros membros da ESF, o que limita suas aprendizagens e oportunidades de agirem em prol da prevenção e promoção em saúde ${ }^{33}$. Ao reconhecer uma limitação ou impasse capaz de prejudicar o trabalho junto ao usuário, é importante que o ACS acione o suporte de outros profissionais da ESF ou busque auxílio mediante a orientação e capacitação com a equipe de especialistas do Núcleo Ampliado de Saúde da Família e Atenção Básica (NASF-AB). Os profissionais do NASF-AB atuam através do apoio matricial, que compreende um modo de realizar a atenção em saúde de forma compartilhada e interdisciplinar, com vistas à integralidade e à resolubilidade da atenção ${ }^{34}$. O apoio matricial amplia a rede de cuidado aos usuários, oferecendo auxílio ao ACS quando seus repertórios de ações não são suficientes diante de casos mais complexos.

A categoria "envolver a família" diz respeito a busca pelo agente da colaboração de familiares no processo de tratamento do usuário, com vistas a corresponsabilidade da família no cuidado. Em muitos casos, percebe-se uma fragilidade do usuário para seguir sozinho com o tratamento, então o agente se utiliza da rede de suporte para melhor auxiliá-lo. Com exceção dos casos em que a pessoa não possui vínculos familiares, integrar a família no tratamento do paciente favorece apoio e motivação para a manutenção da adesão. Além disso, permite esclarecer e conscientizar a família sobre o adoecimento e tratamento necessário, para que se potencialize o cuidado integral ao usuário.

$\mathrm{Na}$ casa dele tem muita coisa para comer e a família teria que entrar numa dieta; ajudar ele nesse controle, mudando os hábitos. Falamos com a mãe que ela precisa mudar para ajudar o filho. É complicado, você está doente, mas sua mãe e seu pai não estão. Então você querer continuar vivendo no mesmo ritmo, só que sem poder. É preciso do estímulo da família, pois ele como adolescente não adere ao tratamento (GFA).

Quando eu ia fazer as visitas ele dizia que esquecia de tomar o remédio, daí eu comecei a pedir ajuda da família. "Eu sei que ele tem que se cuidar, mas vocês também têm que cuidar do pai de vocês". Além do paciente, trabalho a família, agora a própria família informa como está o tratamento do paciente. Contam para a médica se o pai deles está se cuidando (GFB).

O suporte familiar era percebido pelos ACS como potencializador do trabalho da equipe de saúde, na medida em que os familiares constituíam uma rede de apoio acessível e regular para o usuário em situação de cronicidade da doença. De fato, a participação da família tem uma função importante no incentivo a práticas de autocuidado e no oferecimento de segurança e apoio emocional e motivacional a pessoas com enfermidades diversas. A família é comumente reconhecida como um agente facilitador do processo de adesão na medida em que, por exemplo, incentiva a realização de exercícios físicos, a adoção de dieta alimentar adequada e as visitas médicas periódicas ${ }^{28,35}$.

$\mathrm{Na}$ categoria "favorecer acesso a medicamentos e serviços", o agente procurava facilitar o acesso do usuário aos remédios e consultas mediante ações que lhe possibilitasse receber os medicamentos, participar de consultas sem agendamento prévio ou marcar consultas sem estar presente no posto de saúde, em especial quando idosos ou acamados. Por exemplo, o agente deixava os remédios separados na farmácia, solicitava ao médico para deixar os parentes trocarem a receita do paciente e, até mesmo, levava os medicamentos aos usuários quando possível. As falas a seguir ilustram essa categoria: "Pego a receita, para levar a nova com os remédios de volta. Dizem que trabalham e não dá para pegar" (GFC); "Alguns consigo contornar: Vamos lá! Eu marco o exame, eu marco o médico" (GFC).

A composição das categorias mostrou que os participantes, ao se constituírem como agentes de saúde, buscavam alternativas para casos complexos, recorriam à equipe de saúde para a solução ou encaminhamento de problemas identificados para além do seu campo de saber e valorizavam o trabalho em equipe. Tudo isso com o objetivo de favorecer as práticas de cuidado. No entanto, para que sejam mais ativos como agentes de saúde, é importante que tenham capacitação necessária para certas intervenções, sobretudo porque são eles que estão mais presentes no dia a dia com os usuários e nem sempre há tempo ou condições para colocar o outro profissional em cena.

ACS, comumente, mostram insatisfação com a escassez de capacitação e treinamento profissional e colocam demanda para formação continuada. Percebem a capacitação oferecida a eles como insuficiente, com poucos dados da realidade local, enfoque superficial e grande quantidade de informações em período curto. Sendo assim, alguns profissionais sentem-se inseguros em sua prática, pois se deparam com situações e problemáticas de grande complexidade $7,8,10,36$. Diante disso, entende-se que a capacitação contínua dos agentes se apresenta como uma ferramenta eficaz para desenvolver um maior empoderamento deste profissional em suas ações cotidianas.

No entanto, é preciso considerar que nem todas as dificuldades podem ser interpretadas como deficiência na formação dos ACS e que uma das principais contribuições de sua integração nas equipes de saúde reside no saber popular e em permitir a compreensão 
da dinâmica social e das necessidades e demandas da população assistida ${ }^{7}$. Portanto, os cursos de formação devem ocorrer de forma contextualizada e sem ênfase demasiada em conhecimentos científicos sobre doenças e seus tratamentos.

\section{Considerações Finais}

O estudo tornou possível conhecer os repertórios de ação de ACS, evidenciando os desafios e limitações que estes profissionais encontram para lidar com problemas de adesão de usuários hipertensos e diabéticos. Eles revelaram um conjunto de estratégias para responder a problemas identificados no contato com os usuários e, quando julgaram necessário, também procederam a busca de outros profissionais da equipe, em especial médicos e enfermeiros, tanto para fazer encaminhamentos como para discutir e obter orientações a respeito das possibilidades de trabalho.

As ações dos participantes estavam atreladas não somente a um campo teórico de conhecimentos, mas resultavam, em grande parte, de seus tratos diretos e diários com os usuários no território. O fato de os agentes conhecerem de perto a comunidade pode favorecer a condução do cuidado de modo a alcançar boas estratégias para auxiliar na adesão aos tratamentos. No entanto, a sobrecarga de trabalho imposta aos profissionais e a escassez de oferta de cursos de capacitação constituíam empecilhos para uma prática mais eficaz, levando os participantes ao desejo de maiores oportunidades de atualização profissional.

A expectativa é de que estudos como este possam contribuir para a elaboração de diretrizes de intervenção capazes de subsidiar o planejamento de programas de capacitação de ACS. Entretanto, cabe elucidar a limitação do estudo, em razão principalmente do número pequeno de participantes. Os resultados podem ter refletido a realidade do município escolhido, não se aplicando a outras regiões do país. Seria interessante o desenvolvimento de novos estudos com vistas a conhecer o trabalho de ACS em outros municípios, tanto em relação a pessoas com BM e HA, como a outros diagnósticos. Isso possibilitará melhor compreender a importância da atuação desses profissionais no fortalecimento de ações na ABS.

\section{Referências}

1. Brasil. Ministério da Saúde. Portaria GM/MS No 2.436, 21 de setembros de 2017, que dispõe sobre a aprovação da Política Nacional de Atenção Básica, estabelecendo a revisão de diretrizes para a organização da Atenção Básica, no âmbito do Sistema Único de Saúde (SUS). Brasília, MS, 2017. Disponível em https://bvsms.saude.gov.br/bvs/saudelegis/gm/2017/ prt2436 2209 2017.html

2. Stotz EM, David HMSL, Bornstein VJ. O agente comunitário de saúde como mediador: uma reflexão na perspectiva da educação popular em saúde. Rev. APS. 2009 out./dez.; 12(4):487-97.
3. Brasil. Ministério da Saúde. Departamento de Atenção Básica. Política Nacional de Atenção Básica. Série E. Legislação em Saúde. Ministério da Saúde. Brasília, 2012. 110p. Disponível em: http://189.28.128.100/dab/ docs/publicacoes/geral/pnab.pdf

4. Jesus AS, Santos FPA, Rodrigues VP, Nery AA, Machado JC, Couto TA. Atuação do agente comunitário de saúde: conhecimento de usuários. Rev enferm UERJ. 2014 mar./abr.; 22(2):239-44.

5. Bachilli RG, Scavassa AJ, Spiri WC. A identidade do agente comunitário de saúde: uma abordagem fenomenológica. Ciênc. saúde coletiva. 2008 jan./fev.; 13(1): 51-60.

6. Brasil. Lei ${ }^{\circ} 10.507$ de 10 de julho de 2002. Cria a profissão e dá outras providências. Diário Oficial da União 2002; 10 jul.

7. Ribas TC, Benetti SRD. Adesão ao tratamento anti-hipertensivo: visão dos ACS e dos usuários das ESF. Ágora: R. Divulg. Cient. 2011 dez; $18(2): 2-29$

8. Staliano P, Araújo TCCF. Promoção da saúde e prevenção de doenças: um estudo com agentes comunitários de saúde. Rev Psicol Saúde 2011 jan./ jun.; 3(1):43-51.

9. Melo CS, Araújo FF, Martins LV, Nobre LLR, Araújo FM, Rodrigues CAQ. Agente comunitário de saúde: elemento nuclear das ações em saúde. Cien Saude Colet 2013; 18(7):2147-56.

10. Kauling GP, Ceretta LB, Schwalm MT, Dagostin VS, Soratto MT. Utilização de medicamentos: limites e possibilidades das orientações dos Agentes Comunitários de Saúde às famílias. O Mundo da Saúde, 2013; 37(1):44-55.

11. Brasil. Ministério da Saúde. Secretaria de Atenção à Saúde. Departamento de Atenção Básica. DIABETES MELLITUS. Série A. Normas e Manuais Técnicos. Ministério da Saúde. Brasília, 2006. 64p. (Cadernos de Atenção Básica n. 16). Disponível em http://bvsms.saude.gov.br/bvs/ publicacoes/diabetes_mellitus_cab16.pdf

12. Smeltzer SC, Bare BG, Hinkle JL, Cheever KH. Tratado de Enfermagem Médico-Cirúrgica. 10 ${ }^{\mathrm{a}}$ edição. Rio de Janeiro: Guanabara Koogan, 2005.

13. SBD. Sociedade Brasileira de Diabetes. Diretrizes da Sociedade Brasileira de Diabetes: 2019-2020. São Paulo: Clannad, 2019. 491 p. Disponível em: https://www.diabetes.org.br/profissionais/images/ DIRETRIZES-COMPLETA-2019-2020.pdf

14. Brasil. Ministério da Saúde. Secretaria de Atenção à Saúde. Departamento de Atenção Básica. Estratégias para o cuidado da pessoa com doença crônica: diabetes mellitus. Ministério da Saúde. Brasília, 2013. 160 p. Disponível em https://bvsms.saude.gov.br/bvs/publicacoes/estrategias cuidado_pessoa_diabetes_mellitus_cab36.pdf

15. Brasil. Ministério da Saúde. Secretaria de Atenção à Saúde. Departamento de Atenção Básica. Estratégias para o cuidado da pessoa com doença crônica: hipertensão arterial sistêmica. Ministério da Saúde. Brasília, 2013. 128 p. Disponível em https://bvsms.saude.gov.br/bvs/publicacoes/ estrategias_cuidado_pessoa_doenca_cronica.pdf

16. Sociedade Brasileira de Cardiologia. 7a Diretriz Brasileira de Hipertensão Arterial. Arquivos Brasileiros de Cardiologia. 216 set.; 107(Supl. 3). Disponível em http://publicacoes.cardiol.br/2014/diretrizes/2016/05 HIPERTENSAO_ARTERIAL.pdf

17. Brasil. Ministério da Saúde. Plano de Reorganização da Atenção à Hipertensão Arterial e ao Diabetes Mellitus. Ministério da Saúde. Brasília, 2001. 102p. Disponível em https://bvsms.saude.gov.br/bvs/publicacoes/ miolo2002.pdf

18. World Health Organization. Adherence to long-term therapies: evidence for action. Geneva: WHO, 2003.

19. Calvetti PU, Giovelli GM, Gauer GC. Contribuições da psicologia da saúde para a adesão ao tratamento e qualidade de vida de pessoas que vivem com HIV/AIDS. Mudanças - Psicologia da Saúde. 2012 jan./dez.; 20(1-2): $75-80$.

20. Abreu WA, Portela NLC. Fatores associados à não adesão ao tratamento medicamentoso da Hipertensão Arterial Sistêmica. R. Interd. 2015 jul./ago./set.; 8(3):50-60. 
21. Assunção TS, Ursine PGS. Estudo de fatores associados à adesão ao tratamento não farmacológico em portadores de diabetes mellitus assistidos pelo Programa Saúde da Família, Ventosa, Belo Horizonte. Ciênc. saúde coletiva. 2008 dez.; 13(supl. 2): 2189-97.

22. Lima TM, Meiners MMMA, Soler O. Perfil de adesão ao tratamento de pacientes hipertensos atendidos na Unidade Municipal de Saúde de Fátima, em Belém, Pará, Amazônia, Brasil. Rev Pan-Amaz Saude, 2010; $1(2): 113-20$.

23. Tavares NUL, Bertoldi AD, Thumé E, Facchini LA, França GVA, Mengue SS. Fatores associados à baixa adesão ao tratamento medicamentoso em idosos. Ver. Saúde Pública. 2013 dez.; 47(6):1092-101.

24. Martins AG, Chavaglia SRR, Ohl RIB, Martins IML, Gamba MA. Adesão ao tratamento clínico ambulatorial da hipertensão arterial sistêmica. Acta Paul Enferm. 2014; 27(3):266-72.

25. Vásquez IA, Rodriguez CF, Alvarez MP. Manual de Psicología de la Salud. Edição. Madrid: Pirámide. 2003. 288p.

26. Bardin L. Análise de conteúdo. Edição. Lisboa: Edições 70, 1997. $224 \mathrm{p}$

27. Staliano P. Promoção e Comunicação em Saúde: um estudo sobre a atuação de agentes comunitários [Tese de Doutorado]. Brasília (DF): Universidade de Brasília; 2012.

28. Ferreira MA, Iwamoto HH. Determinantes da adesão ao tratamento de usuários com hipertensão cadastrados no programa HIPERDIA da Atenção Primária à Saúde. Rev Min Enferm. 2017;21:e-1037.

29. Barros S, Oliveira MAF, Silva ALA. Práticas inovadoras para o cuidado em saúde. Revista da Escola de Enfermagem da USP. 2007 dez.; $41: 815-819$.

30. Pierin AMG, Mion D, Fukushima JT, Pinto AR, Kaminaga MM. O perfil de um grupo de pessoas hipertensas de acordo com conhecimento e gravidade da doença. Rev Esc Enf USP. 2001 mar.; 35(1):11-8.

31. Coelho EB, Neto MM, Palhares R, Cardoso MCM, Geleilete TJM, Nobre F. Relação entre a assiduidade às consultas ambulatoriais e o controle da pressão arterial em pacientes hipertensos. Arq. Bras. Cardiol. 2005 set.; 85(3):157-61

32. Crevelim MA, Peduzzi M. A participação da comunidade na equipe de saúde da família. Como estabelecer um projeto comum entre trabalhadores e usuários? Ciênc. saúde coletiva. 2005; 10(2):323-31.

33. Santos CW, Farias Filho MC. Agentes Comunitários de Saúde: uma perspectiva do capital social. Ciênc. saúde coletiva 2016; 21(5):1659-1667.

34. Campos GWS, Domitti AC. Apoio matricial e equipe de referência: uma metodologia para gestão do trabalho interdisciplinar em saúde. Cadernos de Saúde Pública, 2007 fev.; 23(2):399-407.

35. Barreto MS, Marcon SS. Participação familiar no tratamento da hipertensão arterial na perspectiva do doente. Texto Contexto Enferm, 2014 jan./mar.; 23(1):.38-46

36. Bachilli RG, Scavassa AJ, Spiri WC. A identidade do agente comunitário de saúde: uma abordagem fenomenológica. Ciência \& Saúde Coletiva. 2008 jan./fev. 13(1):51-60. 